\title{
Using XFEM Techniques to Predict the Damage of aluminum 2024T3 notched under tensile load
}

\author{
Benzaama Abdallah \\ University of Science and Technology of Oran, LSIM Laboratory, USTOMB, Oran, Algeria \\ abenzaama@yahoo.com \\ Mokhtari Mohamed \\ National Polytechnic School of Oran M.A., ENPO, LaRTFM Laboratory, Oran, Algeria \\ Mokbtarimohamed44@yahoo.com
}

Benzaama Habib, Abdelouahed Elamine

National Polytechnic School of Oran M.A., ENPO, LABAB Laboratory, Oran, Algeria

habenza@yahoo.fr, heabamine@gmail.com

Tamine Tawfik

University of Science and Technology of Oran, LSIM Laboratory, USTOMB, Oran, Algeria

tamine63@yahoo.fr

Madani Kouider

University of Djillali Liabess, Laboratory LMPM, Sidi Bel Abbess, Algeria

Slamen Amir, Ilies Mrabet

National Polytechnic School of Oran M.A., ENPO, LABAB Laboratory, Oran, Algeria

slamene.amir@outlook.com, iliesmrabet@yahoo.fr

ABSTRACT. The objective of this work is to analyze some geometrical effect to predict the damage of aluminum 2024T3 structure after validate numerical model by experimental test. The mechanical of damage behaviour under tensile tests of several plates with notches of various forms are investigated using an XFEM technique. The finite element analysis is performed to determine the failure load of these plates. Four different form of notched plates in another part of this work are reinforced by a thickness augmentation with different shapes around the notch. The results of the tensile analysis show that the reinforcements gives the best increase in failure load of each plates.

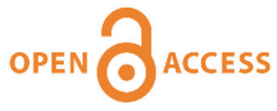

Citation: Benzaama, A., Mokhtari, M., Benzaama, H., Abdelouahed, E., Tamine, T., Madani, K., Slamen, A., Ilies, M., Using XFEM Techniques to Predict the Damage of aluminum 2024T3 notched under tensile load, Frattura ed Integrità Strutturale, 50 (2019) 184-193.

Received: 29.04.2019

Accepted: 24.07.2019

Published: 01.10.2019 
KEYwORDS. Failure load; Damage; Notch; XFEM.

\section{INTRODUCTION}

$\mathrm{S}$

tructures used in aeronautical, aerospace and aircraft are often exposed to extreme operating conditions, overload, fatigue and other reasons in service or because of internal defects [1]. This type of structure are always suffering quick damage and failures starting with local microcracks and defaults that make their service life limited [2]. Geometric discontinuities (a notch or abrupt change in structural geometry) are causes of the reduction of the load bearing section and the local amplification of stress near the discontinuity. Patch repair of damaged composite parts bonded with an adhesive film [3] and one of the techniques that significantly extend the service life of these damaged structures [4,5]. The present work uses numerical validation framework of the research works experimentally carried out by Madani et al. [6] who analyzed five different forms of notches in aluminum plates repaired by composite patches. They compared with unrepaired plates and they found that the reduced repair mean of $20 \%$ damage for all models. At first Kirsh studied in 1898 [7] the distribution of stress around a hole, Later several researchers have focused their research on increasingly complex geometries such as Neuber [8] and Peterson [9]. The research aims to understand the phenomenon of initiation and propagation of cracks to predict the life of aeronautical structures.

Torbani [10] investigated the damage of an $\mathrm{O}, \mathrm{U}, \mathrm{V}$-shaped slotted plate where he used the point stress criterion combined with the equivalent material concept, he concluded that the accuracy of each failure criterion depends on essentially the characteristic of the notch and therefore the distribution of stresses around the edge of the notch. Other researchers such as berto and all [11] have worked on uniaxial and multiaxial fatigue for different types of notches. The approach is based on strain energy density (SED) of a steel and aluminum alloys structure to tension, torsion and combined tension and torsion. They demonstrated that a linear elastic analysis allows to summarize all the high phases of the given cycle of fatigue resistance using a single SED value. Torabi's other works with Mohammad Hosseini [12] have experimentally and theoretically studied U-slotted Al 7075-T6 plates under the mixed loading mode (I / II). The concept of equivalent material (EMC) is used in conjunction with the criterion of maximum tangential stress (UMTS) and mean stress UMS. They showed that the experimental failure loads are well predicted using the UMTS-EMC calculation and UMS-EMC criteria. Also, the work of Mohammad Rez [13] on the resistance of friction malaxed welded joints containing notches at right angles in the interface of the joints of welded plates and tested under a three-point bending in order to study the resistance to interface rupture of $\mathrm{Al}$ - Cu joints. They also showed that the highest breaking loads were obtained at low spindle speeds.

One of the most important parameters is the stress intensity factor for estimating the life of the cracked structure; the Paris model describes the growth rate of fatigue cracks, the integral J technique and the extended finite element method [14] can all be realized using theoretical or numerical techniques. Researchers are still trying to understand the phenomenon of crack initiation and propagation, which terminates the lifespan of aeronautical structures. The advantage of the XFEM technique is that initiation and propagation are not chosen, but other criteria such as the cohesive element and the VCCT criterion require a choice to locate the separation surfaces. Even more, the mesh does not need to be updated to follow the crack path. This path creates partitions in the elements as they can take adjacent elements hence the importance of mesh optimization. This is why other researchers are using this technique to numerically analyze damage to structures where it can be used to repair patches. XFEM crack modeling was introduced by Sukumar et al [15], who solved several problems of planar crack mode-I. They showed that this method compares with analytical solutions. XFEM is used to perform crack propagation analysis, which is not feasible in practice by conventional FEM that often requires remeshing procedures [16$17-18]$.

The objective of this study is to evaluate by numerical simulation the effect of dimension and localization of notch on resistance of a plate type Aluminum under damage behavior by tensile load. Four geometrical notches have been selected with different dimensions in order to see their effect on the failure load of the plate. We also put into consideration the augmentation of résistance by reinforcing the plate around the notch. The analysis of the numerical results show that the failure load increases as the notched plate has reinforced geometric around the notch. 


\section{ANALYSIS}

\section{Numerical parameters analysis and result validation}

A three-dimensional numerical analysis in tensile loaded with four geometrical notch model (Fig.1) has been studied. In the first part and in the second part as solutions, plates with forms of reinforcement at the notch were used. A nonlinear material and geometrical analysis were performed, in tensile behavior the restraining and loading condition consists on applying a restraint in the edge and tensile displacement at the opposite edge.

The dimensions of the simulated specimen are $2 \mathrm{~mm}$ in thickness in the first case, $140 \mathrm{~mm}$ in length and $50 \mathrm{~mm}$ in width. It contains in the first three different forms of a central notch and one on the edge. In the second case, it has three modifications of reinforced forms around the notch when the thickness are elevated to $0.25 \mathrm{~mm}$.

\begin{tabular}{llll}
\hline B(elliptical) & e(circular) & c(elliptical) & $\mathrm{f}($ V lateral $)$ \\
$\mathrm{H}=140 \mathrm{~mm}$ & $\mathrm{H}=140 \mathrm{~mm}$ & $\mathrm{H}=140 \mathrm{~mm}$ & $\mathrm{H}=140 \mathrm{~mm}$ \\
$\mathrm{~W}=50 \mathrm{~mm}$ & $\mathrm{~W}=50 \mathrm{~mm}$ & $\mathrm{~W}=50 \mathrm{~mm}$ & $\mathrm{~W}=50 \mathrm{~mm}$ \\
$\mathrm{a}=20 \mathrm{~mm}$ & $\mathrm{D}=20 \mathrm{~mm}$ & $\mathrm{a}=20 \mathrm{~mm}$ & $\mathrm{a}=20 \mathrm{~mm}$ \\
$\mathrm{~b}=1 / 4 \mathrm{a}$ & $\mathrm{D}=20 \mathrm{~mm}$ & $\mathrm{~b}=1 / 2 \mathrm{a}$ & $\mathrm{b}=\mathrm{a}$ \\
\hline
\end{tabular}

Table 1: Structures forms dimensions.

The materials structure used for testing is Aluminum 2024T3, its tensile curve and the different mechanical properties are given in Fig. 2, and taken directly from the experimental testing by MADANI [6]. These materials are used in the aerospace industry given its important mechanical characteristics. To simulate the crack onset and it is growth as well as to obtain the failure load by damage of the structure, a non-linear behaviour of the materials has been using.
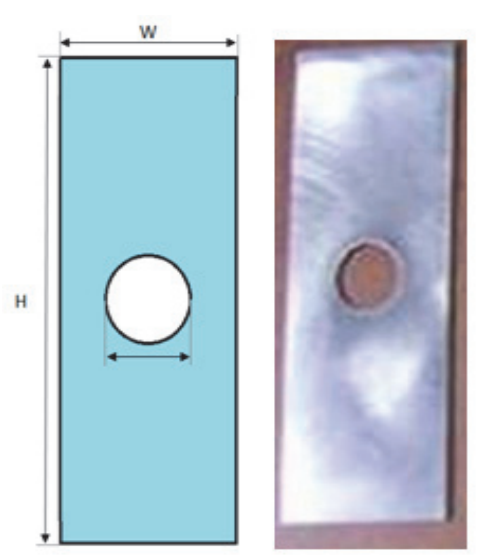
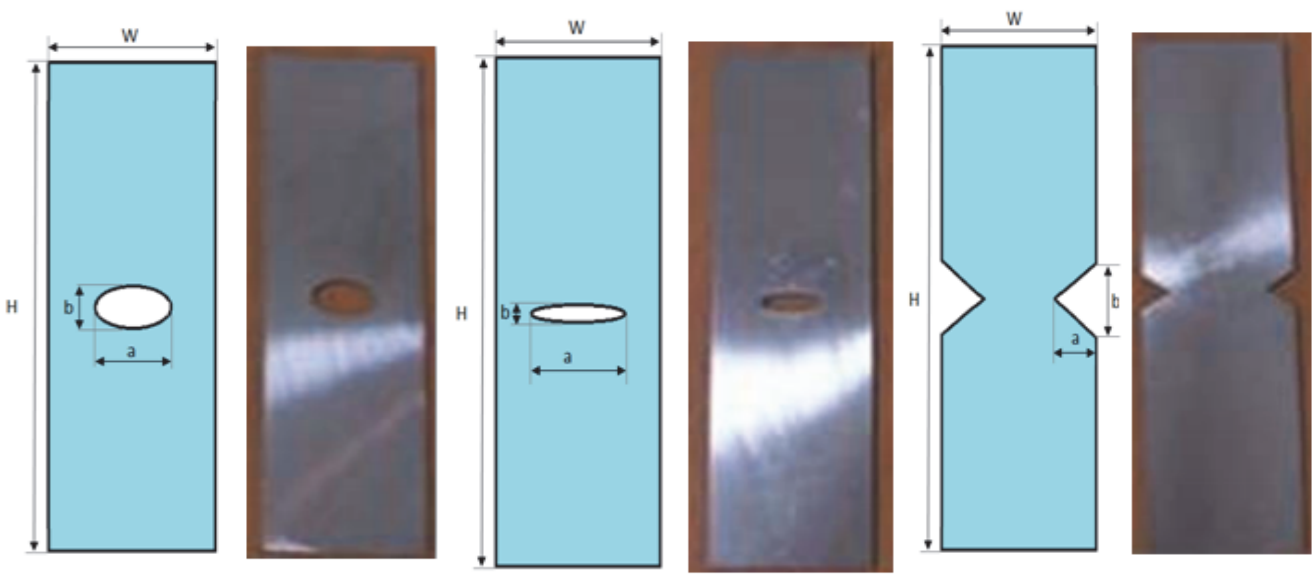

Figure 1: Geometry of notched structure.

The damage scenario is modeled in the heart of the structure using XFEM technique where it is necessary to introduce the mechanical parameters listed in fig.2.

The structure domain is created as a solid with enrichment elements X-FEM introduced according to the input order as follows:

$*$ Enrichment, name $=$ Crack -1, type $=$ PROPAGATION CRACK, activate $=$ ON

The evaluated damage is maximal at crack opening and is calculated using the following equation [19]:

$$
\delta_{n}=\sqrt{\left(\delta_{n}^{2}+\delta_{s}^{2}+\delta_{t}^{2}\right)}
$$




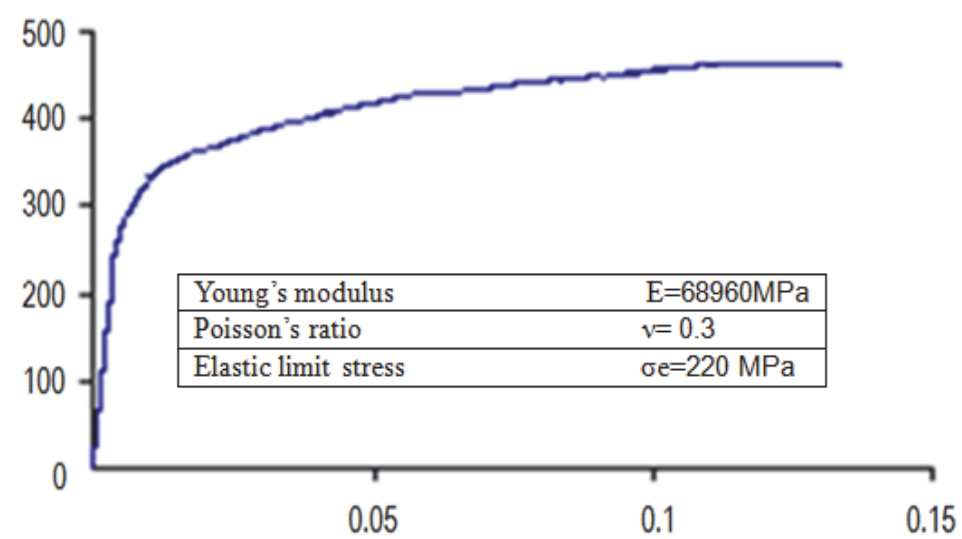

Figure 2: Mechanical properties of the adherents used [6].

In this study, the following analysis uses the elastic properties presented in Fig. 2. The maximum principal stress is the value of the un-notched nominal strength which is measured as (456) MPa. In addition, the damage evaluation criterion is maximum traction displacement (maximum crack opening of Aluminum measured as $0.14 \mathrm{~mm}$ ). Therefore, the input file of the order line in the software becomes as follow:

$*$ Damage Initiation, criterion = MAXPS

$*$ Damage Evolution, type $=$ DISPLACEMENT

*Damage Stabilization 1e-5

In the numerical finite element calculations, the choice of mesh is important in order to have the computational convergence with reliable results translated by the number of the nodes and their disposition, which characterizes the element and its density in the mesh structure. The meshes used in this analysis constructed with non-uniform and bias effects then swept technique using (C3D8R) element type. A dense mesh is generated in regions around the notch in order to capture the peak stresses which practically presented concentration stress and initiation of crack grow whereas coarser structure meshing is used for the other domain region of the mesh, to reduce the calculations time. The section through thickness is simulated using only one dependent section to help node set convergence.
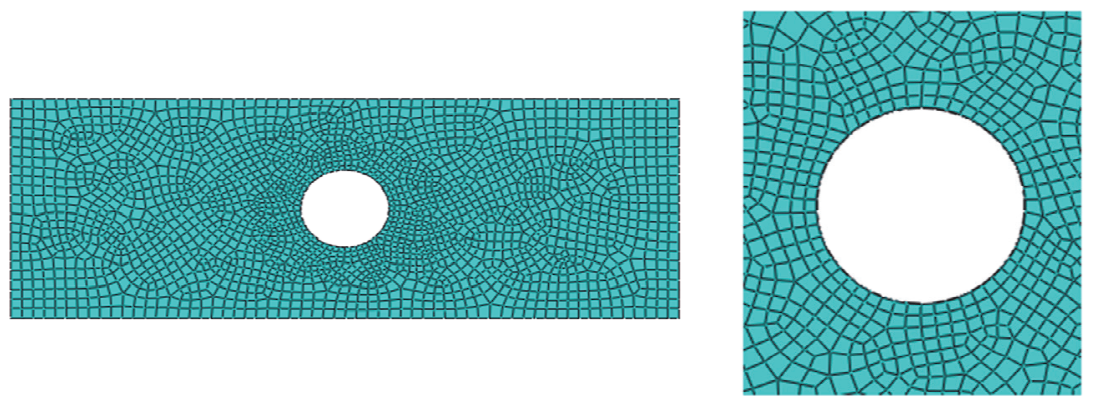

Figure 3: Example of circular notch (size1.8) in the non-uniform rectangular mesh.

It is important to describe the initiation zone and the crack propagation path. This latter can relatively influence the value of the damage force and depends mainly on the architecture of the mesh. The experimental curve-force-displacement result was compared twice, first by the choice of the element (Fig. 4), then by the architecture of the mesh conditioned by the shape of the notch as well as by the conditions at the limits.

The Figs. 5 also show that the larger the dimension of the notch, the greater the stress concentration that results thereafter, which causes rapid damage.

We use the same conditions (sizing of the structure, properties of the material used and the boundary conditions) for the convergence of the mesh. The validation of the results with the experimental one is based much more on the force of damage; see Madani et al. [6]. We compared the experimental results with those obtained by numerical computation in order to validate a reliable numerical approach and evaluate other parameters forming part of the objective of this analysis as if solutions, such as the geometric form of reinforcement at the level of these notches, (see Fig. 6). 


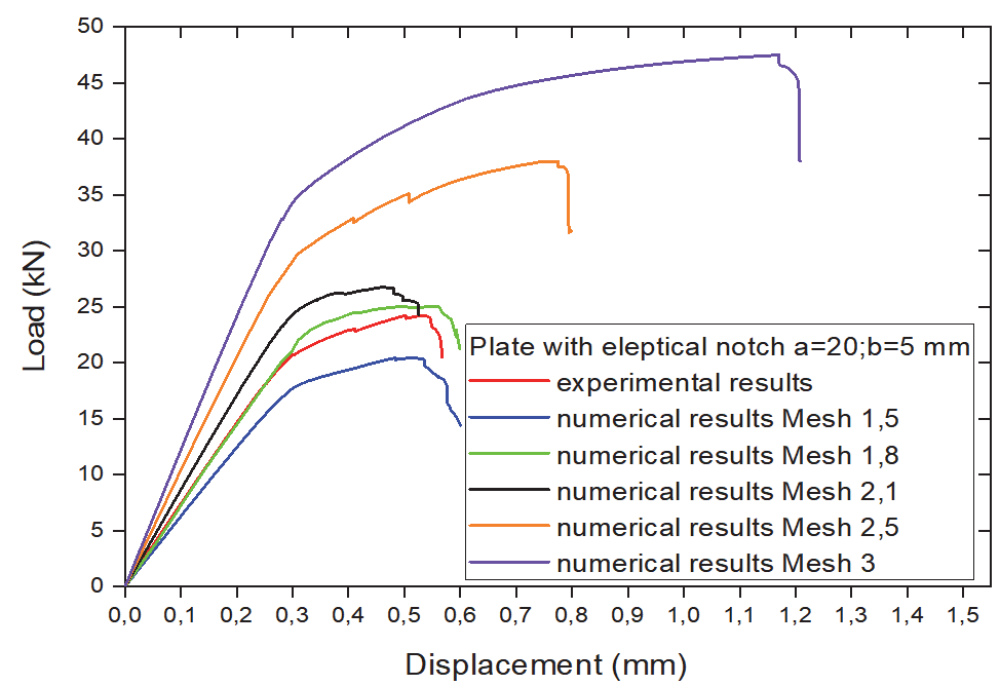

Figure 4: Mesh convergence.

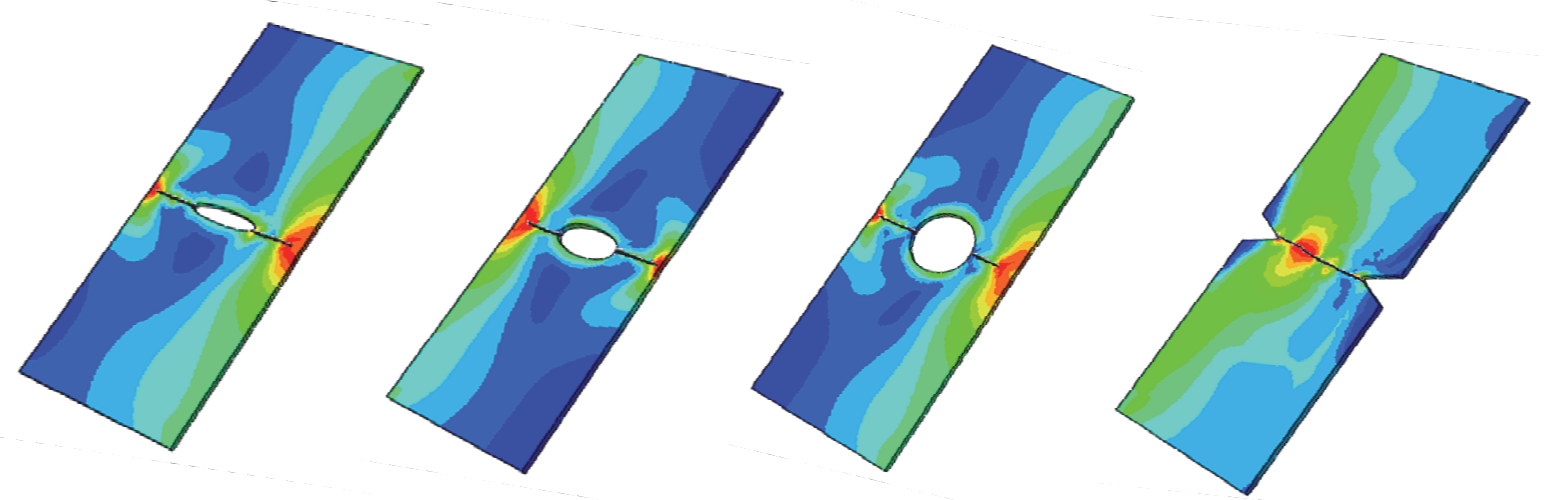

Figure 5: Representation of the crack propagation path.

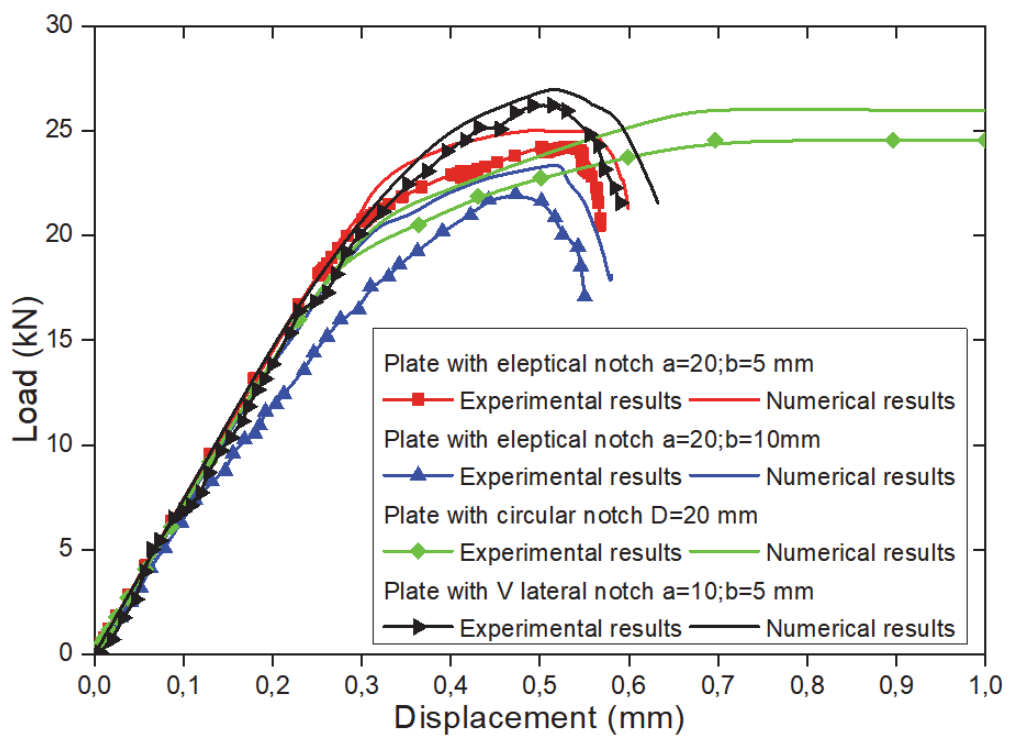

Figure 6: Comparison of experimental and numerical results for different cracks. 
Fig. 6 shows the numerical and experimental results of all the forms of notches of the studied plates are presented. Experimental results are presented with lines, symbols, and numerical results with only lines. Note that the numerical results are presented with the same gaits but with an error that varies according to the size of the crack. The mesh effect is still relevant, it is of the order of $3.59 \%$ for the elliptic crack a $/ \mathrm{b}=4,6.28 \%$ for the elliptic crack a $/ \mathrm{b}=2,5.93$ for the round crack and $3.11 \%$ for lateral $\mathrm{V}$ notch. Note that the calculated absolute error is taken at the level of the damage force (maximum force).

\section{Effect of the crack form}

A comparative analysis has been made between experimental and analysis solutions, where load-displacement curves are presented in the same figures to better show the effect of the crack form and its reinforcement. All the structures are loaded up to their failure with a speed of identical loading numerically at identical increments. The presence of the notch in the structures weakened its resistance where it causes a concentration of stresses which results in the birth of a crack, the resolution of this problematic can take place by a geometric reinforcement.

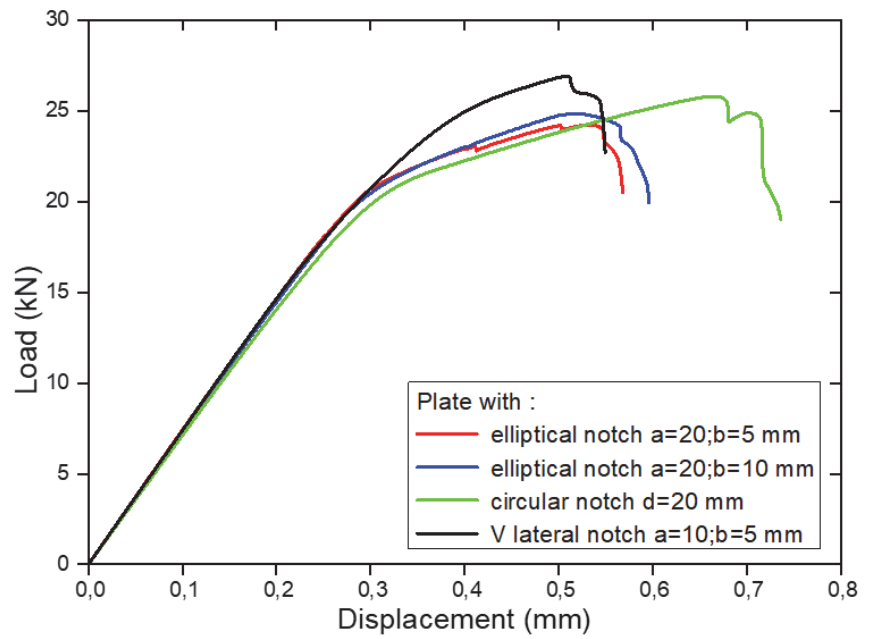

a)

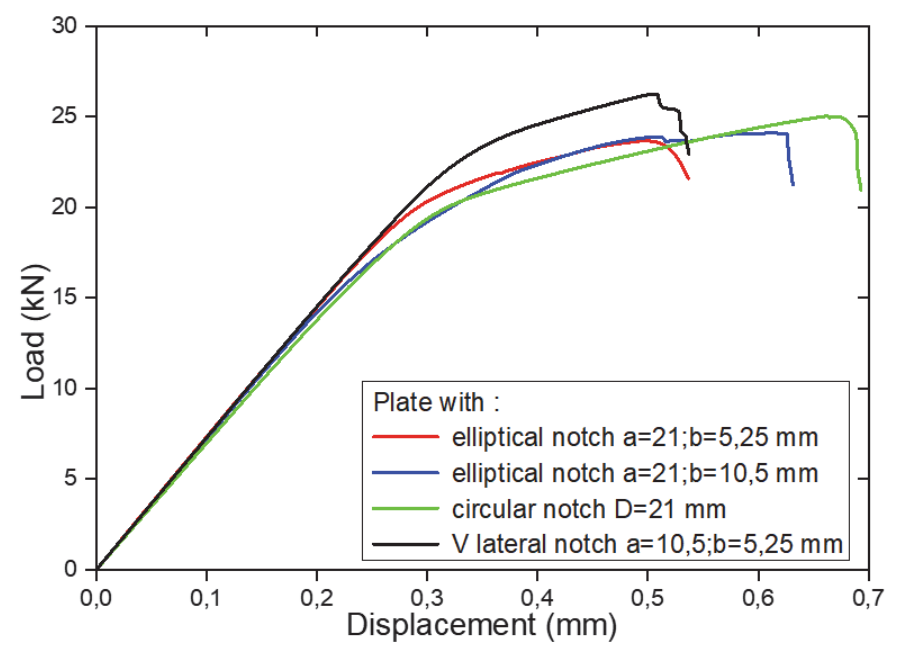

b)

Figure 7: Effect of different crack form.

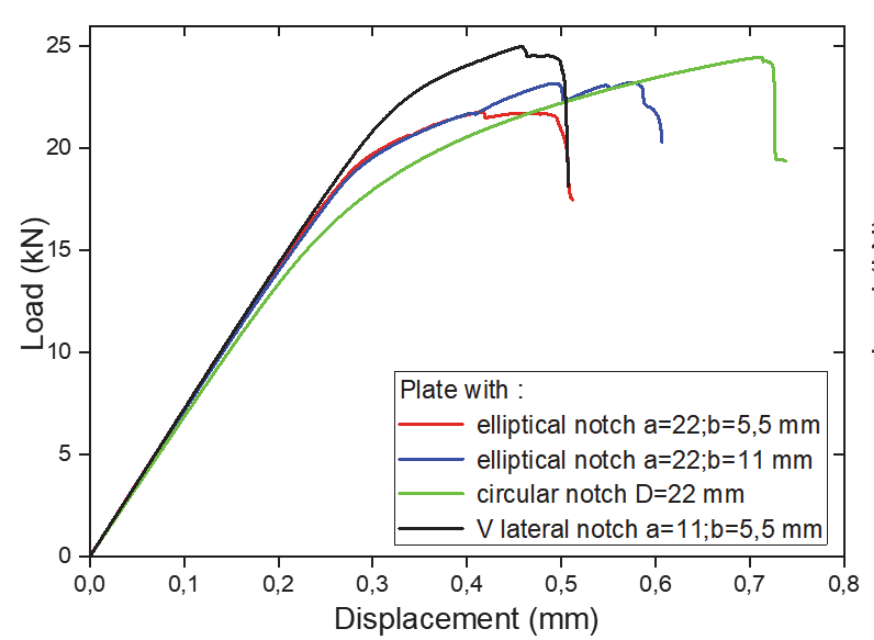

a)

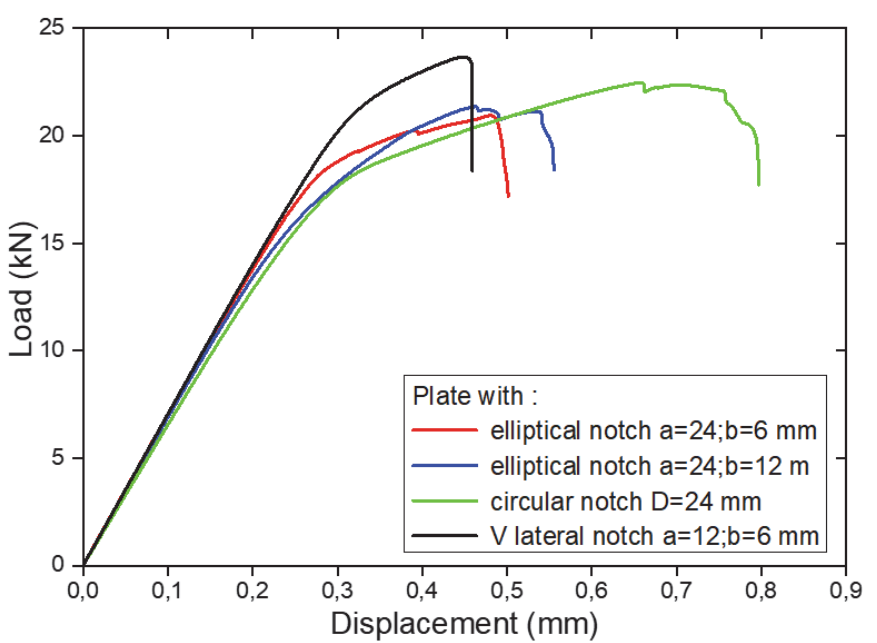

b)

Figure 8: Effect of the crack form.

Fig. 7 shows the failure load for different forms of the notch. In this figure, the failure load is conditioned by the shape and size of the notch. In our analysis, the same rigidity of the structure resulted in the same slope of the elastic portion. The effect of the notch is present in the field of plasticization. As the plastic field increases, the stresses decrease by absorption and the length of structure increases. The figures show that over the elliptical notch becomes rounder stress decreases the 
notch. The crack propagation takes the direction from the inside to the outside for the notches in the center of the plates (elliptical a / b = 4, elliptical a / b = 2 and round), on the other hand for the lateral V notch which is at the end, it takes the opposite effect of the load more quickly.

The Figs. 7 and 8 show not only the comparison between different forms of notches but also the effect of their dimensions. They show us a fast damage (low failure-load) with less rigidity for the dimensions of the notch, which are important. The plate with the shape of circular notch, has a significant plasticization (more elongation), unlike that in lateral V because it causes quickly the propagation of the crack. The initiation of the crack always takes the stress concentration zone.

\section{Effect of the reinforced notch form}

Patch reinforcement is used for the repair of cracked structures. In order to evaluate the dependent parameters, the numerical model was validated in the first part.

\begin{tabular}{clll}
\hline Rectangular & Horizontal & Vertical & Round \\
$\mathrm{a}=50 \mathrm{~mm}$ & $\mathrm{a}=50 \mathrm{~mm}$ & $\mathrm{a}=38.21 \mathrm{~mm}$ & $\mathrm{~d}=43.71$ \\
$\mathrm{~b}=30 \mathrm{~mm}$ & $\mathrm{~b}=38.21$ & $\mathrm{~b}=50 \mathrm{~mm}$ & \\
\hline
\end{tabular}

Table 2: Dimension of different reinforcement forms.

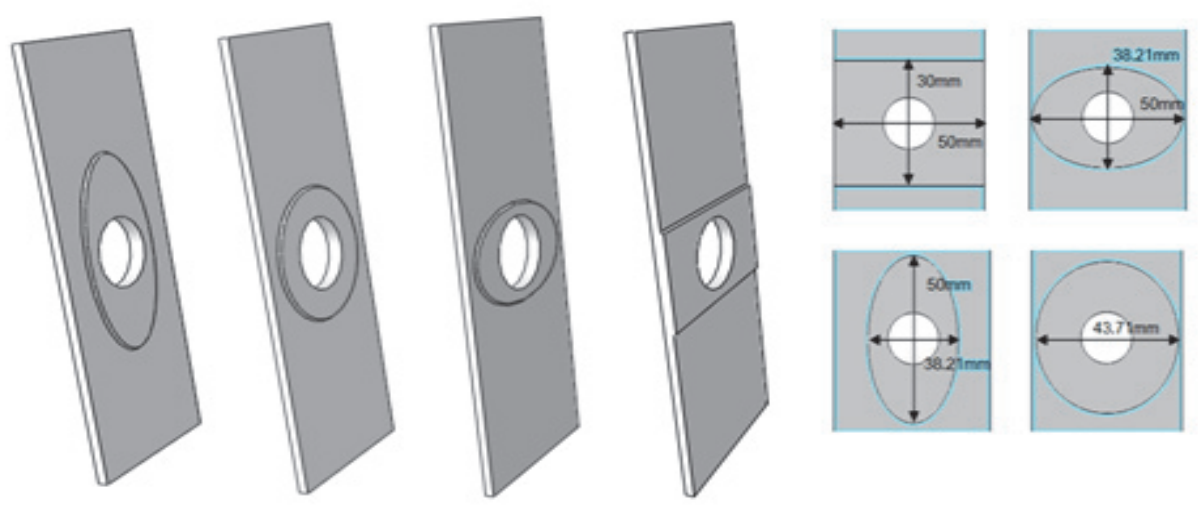

Figure 9: Dimension of different forms of reinforcement.

The purpose of the parametric study presented in this section is to reduce the stress concentration and then increase the resistance to damage. We therefore opted for geometric and dimensional reinforcement structures at the notch. The important condition we have targeted is the added volume of material, which is $1500 \mathrm{~mm}^{3}$. This condition must be the same to face a fair comparison and, therefore, only the form that takes effect, to which the reinforcing thickness must be identical. It is clear that there are areas, which are more stressed than others by the form of reinforcement. The critical zone presents itself in these models, according to the width of the plates in the vicinity of the notch. The non-reinforcing model was also presented in the curves as a comparison to reinforcement efficiency. We are also interested in the reinforcement shape effect that we analyzed.

This Fig. 10 shows that each reinforcement shape increases the value of the damage force from $5 \mathrm{kN}$ to at most $11 \mathrm{kN}$ at the maximum. This improvement can be more remarkable for significant thicknesses of these reinforcements. The elastic domain of the curves has slightly different slopes, these results in an increase in rigidity of the reinforced plates. The figure also shows that in the plastic field, the reinforcement curves for the rectangular, horizontal elliptical, vertical elliptical and round shape are offset and the same pace because the effect is purely dimensional. Given the shape of the notch, the horizontal and horizontal elliptical reinforcing shapes are slightly stronger than the others.

This figure shows that the notch and reinforcement shape increase the value of the damage force only up to $5 \mathrm{kN}$ at most. It is noted that there is an interdependence between the shape effect of the notch and the reinforcing shape effect, which results in the reduction of the plastic part. The following figure shows that the rectangular reinforcement shape with the horizontal elliptical shape retains the strength advantage in the first place because this reinforcement occurs along the entire cross section of the plate. 


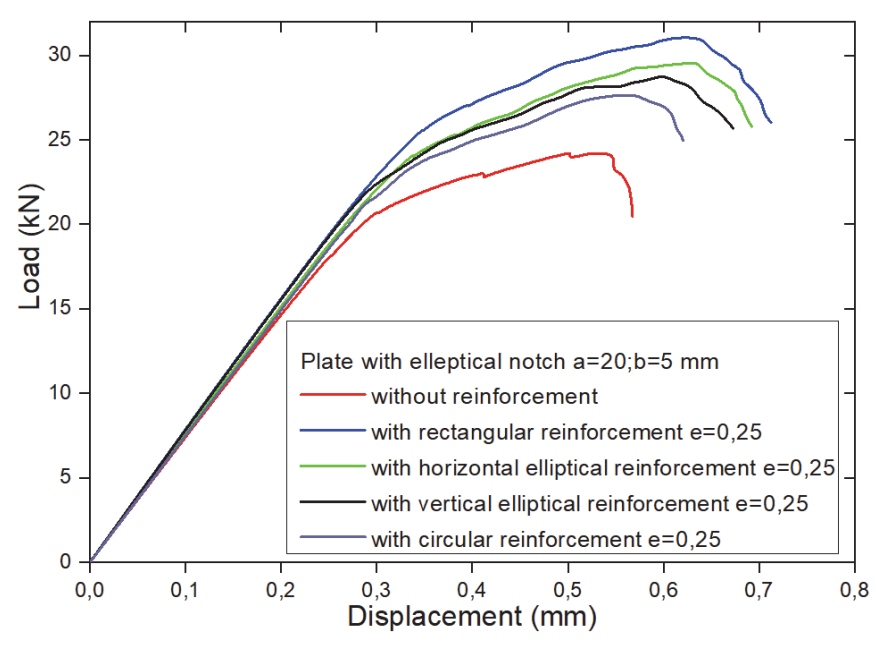

Figure 10: Effect of reinforcement forms for the elliptical notch a / $\mathrm{b}=4(\mathrm{a}=20, \mathrm{~b}=5)$.

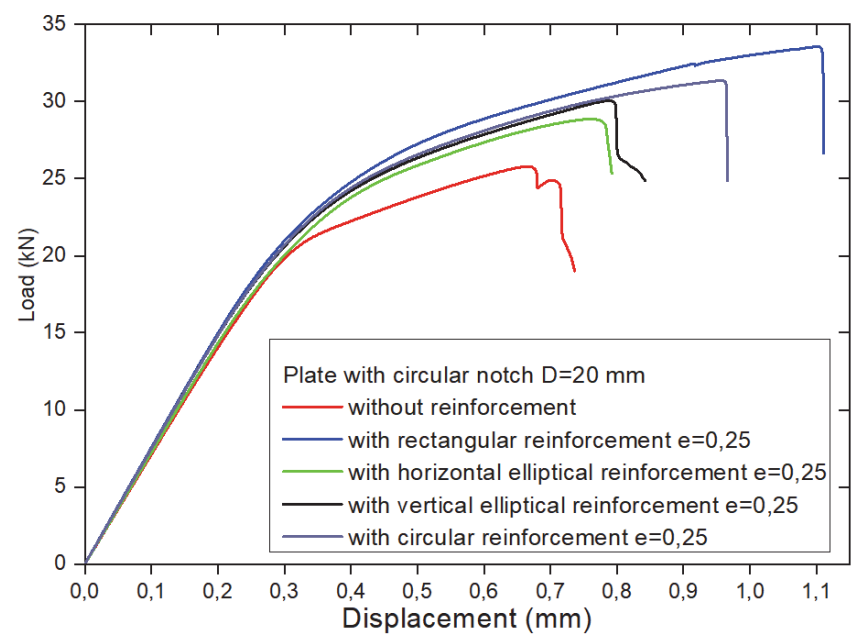

Figure 12: Effect of reinforcement shapes for the round notch D $=20$.

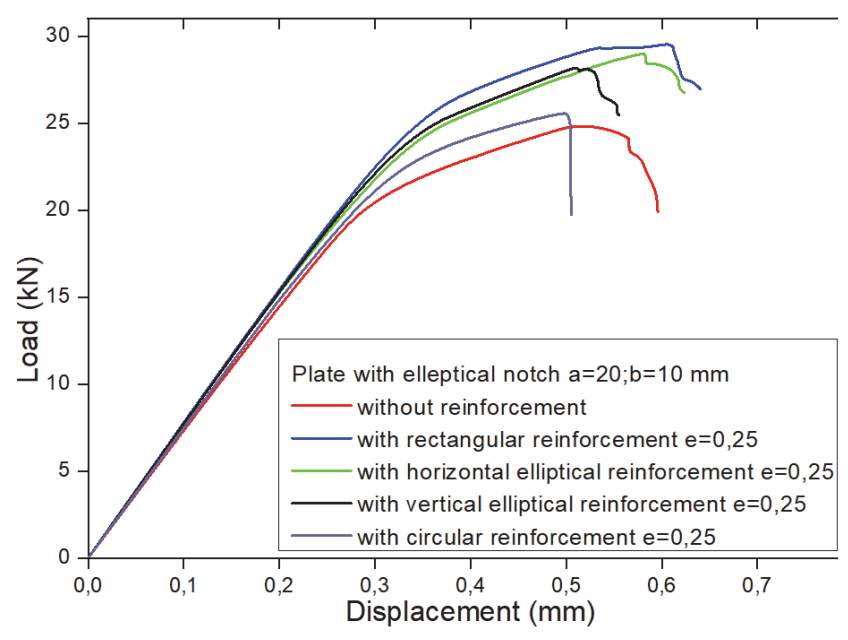

Figure 11: Effect of reinforcement forms for the elliptical notch $a / b=2(a=20, b=10)$.

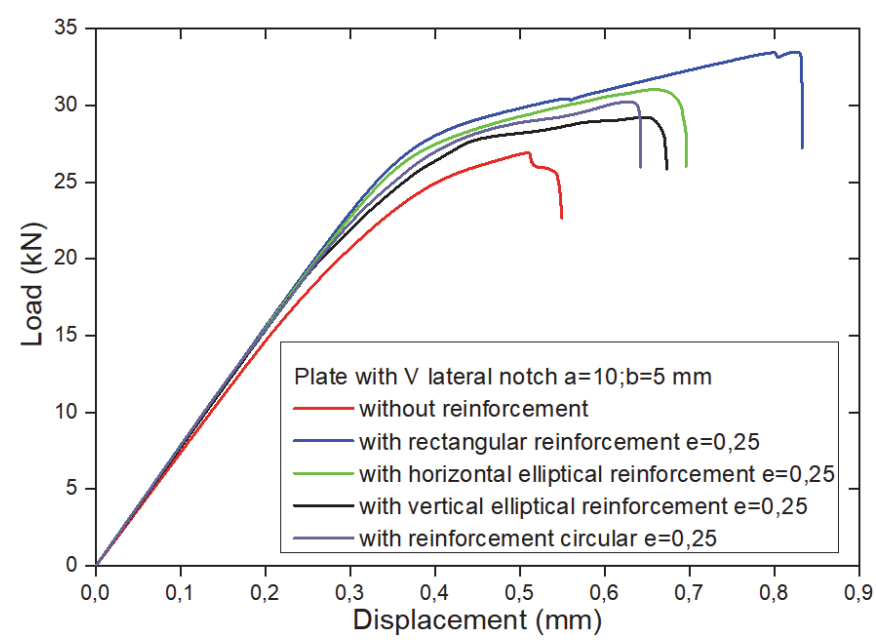

Figure 13: Effect of reinforcing shapes for the notch round $\mathrm{D}=$ $20 \mathrm{~mm}$.

From Fig. 12, we can say that with this notch shape, the reinforcements increase the value of the damage force up to $12 \mathrm{kN}$ maximum. Note also that the effect of reinforcing shape and more important than the shape effect of the notch which results in an ordered variation, or the rectangular shape and always advantageous followed by the round reinforcement shape unlike other cases Figure (notch and reinforcement of the same shape), follows the vertical elliptical shape, finally horizontal elliptical. The peculiarity of these cases is that the increased damage force results in an increase in elongation with the same appearance noticed.

Fig. 13, shows the form of notch with the presence of reinforcement causes the damage resistance to increase up to a maximum of $7 \mathrm{kN}$. The figure shows that the shape effect of the notch and reinforcement are close together. The damage force increases with increasing elongation except for the vertical elliptical reinforcement form. For this notch shape, the figure shows that the rectangular reinforcement shape with the horizontal elliptical shape is always the strongest because these reinforcements follow the cross section.

\section{RESULTS COMPARISON}

$\mathrm{I}$ $\mathrm{n}$ the comparison of the results, the interdependence of the two parameters of the notch and its reinforcement, the latter are grouped in the same figure. This figure represents a comparison between the failure load values for different 
type of notch and for different configurations of the reinforced. In each form of reinforcement the results always remain beneficial but with a different effectiveness.

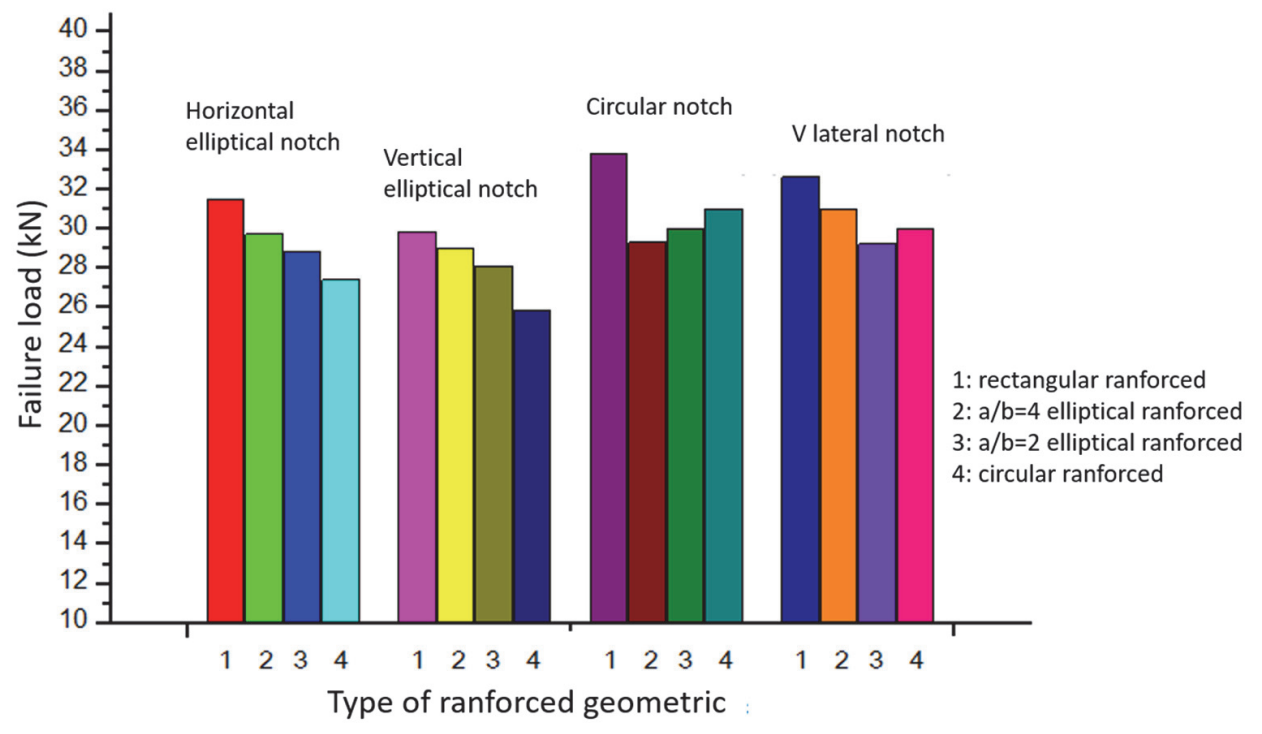

Figure 14: Synthesis effective forms of notches and reinforcement.

From the Fig. 14, the different forms of reinforcement for the shape of the circular and lateral notch have fracture curves, which are a little higher if compared with other forms of vertical and parallel elliptical notches. Therefore, we notice that these structures are more resistant. If we compare them by the form of reinforcement for each model, we find that the rectangular form is the most resistant by contribution to the others.

\section{CONCLUSION}

$\mathrm{I}$ $\mathrm{n}$ This study, it had been used a numerical simulation based on the Extended Finite Element Technique (XFEM) of a structure notched. The following underlined conclusions has been deduced from the obtained results:

- The concentration of the stresses at the notch as well as the curves of rupture depend strongly on the type of notch and the form of reinforcement.

- These modifications of the forms of reinforcement bring an improvement on the resistance of the plates, which can go up to $11 \mathrm{kN}$.

- An interdependence of effect (reinforcement shape and notch shape) has been observed, and which acts in the positive and sometimes negative direction all depends on the case that appears between the shape of the cut and the shape of the cut enhancement.

- The numerical computation model is strongly based on the experimental results.

- The XFEM method is highly dependent on the mesh. The initiation and crack propagation path also depends on it.

- The shape of reinforcement also influences the size of the plastic zone.

- All models with reinforcement take crack initiation at the end of the notch from the inside to the outside for the notches that are at the center of the plate and from the outside to the inside for the notches at the end of the plate.

- When the structure is loaded, the resistance of the notched structure is limited by its size and shape.

\section{REFERENCES}

[1] Chapuis, B., Osmont, D. (2010). Contrôle santé intégré par méthode ultrasonore des réparations composites collées sur des structures métalliques. Laboratoire Ondes et Acoustique - ESPCI, Université Paris 7, CNRS UMR 7587. 
[2] Pastor, M.L., Balandraud, X., Grediac, M., Robert, J.L. (2008). On the fatigue response of aluminum specimens reinforced with carbon-epoxy patches. Composite Structures, 83, pp. 237-246.

[3] Baker, A. (2008). Structural health monitoring of a bonded Composite patch repair on a fatigue Cracked F- 111C Wing Defense Science and Technology Organization (Australia).

[4] Baker, A., Francis, R., Rhys, J. (2003). Advances in the Bonded Composite Repair of Metallic Aircraft Structure. 1, Elsevier.

[5] Emin, E., Süleyman, T.G., Mzaffer, T. (2010). Fatigue and fracture analysis of aluminum plate with composite patches under the hydrothermal effect. Composite Structures, 92, pp. 2622-2631.

[6] Madani, K., Touzain, S., Feaugas, X., Cohendouz, S., Ratwani, M. (2010). Experimental and numerical study of repair techniques for panels with geometrical discontinuities, Computational Materials Science, 48, pp. 83-93.

[7] Lieurade, H. P., Jian, L. U. (2012). Concentration de contraintes. Ed. Techniques Ingénieur.

[8] Neuber, H. (1961). Theory of Notch Stresses, Office of Technical Services.

[9] Peterson, R.E. (1974). Stress Concentration Factors, John Wiley \& Sons. New York, 150, pp. 34.

[10] Torabi, A. (2013). The equivalent material concept: Application to failure of O-notches. Engineering Solid Mechanics, 1(4), pp. 129-140.

[11] Berto, F., Torgersen, J., Campagnolo, A. (2017). A review of the fatigue strength of structural materials under multiaxial loading in terms of the local energy density. Engineering Solid Mechanics, 5(4), pp. 245-270.

[12] Torabi, A., Hosseini, B. (2017). Large plasticity induced crack initiation from U-notches in thin aluminum sheets under mixed mode loading. Engineering Solid Mechanics, 5(1), pp. 39-60.

[13] Fotouhi, Y., Berto, F. (2018). Experimental notched fracture resistance study for the interface of Al-Cu bimetal joints welded by friction stir welding.

[14] Gopichand, A., Kumar, M. S. and Sharma, A. V. N. L. (2012). Computation of Stress Intensity Factor of Cracked Aluminum Plate Using Virtual Crack Closure Technique, International Journal of Engineering Research and Applications, 2(6), pp. 460-465.

[15] Sukumar, N., Moes, N., Moran, B. and Belytschko, T. (2000). Extended Finite Element Method for Three-Dimensional Crack Modeling, International Journal for Numerical Methods in Engineering, 48(11), pp. 1549- 1570.

[16] Nagashima, T. and Suemasu, H. (2010). XFEM Analyses of a Thin-Walled Composite Shell Structure with a Delamination, Computer and Structure, 88(9-10), pp. 549-557.

[17] Sukumar, N., Chopp, D. L., Moës, N. and Belytschko, T. (2001). Modeling Holes and Inclusions by Level sets in the Extended Finite Element Method, Computer Methods in Applied Mechanics and Engineering, 190(46-47), pp. 61836200.

[18] Stolarska, M., Chopp, D. L., Moës, N. and Belytschko, T. (2001). Modeling Crack Growth by Level Sets in the Extended Finite Element Method, International Journal for Numerical Methods in Engineering, 51(8), pp. 943-960.

[19] ABAQUS, Abaqus Version (2009). “6.9 Documentation.” Providence, RI: Dassault Systems Simulia Corporation. 